\title{
Com a Palavra, o Autor: A Relevância do Componente Semiológico na Enunciação da Personagem Teatral
}

\section{*Paulo Ricardo Berton}

\section{Resumo}

Este artigo recupera a importância do aspecto semiológico da enunciação da personagem teatral, que, em conjunto com seu aspecto fenomenológico deve compor uma totalidade inseparável no momento da recepção de um texto dramático através da encenação teatral. Para tanto, se resgata a palavra enquanto ferramenta básica do dramaturgo, seguido da análise de cinco fragmentos iniciais de obras de diferentes autores e períodos, para se verificar a pertinência da tese levantada quanto ao valor do componente semiológico da enunciação no texto dramático.

Palavras-chave: semiologia texto dramático - enunciado teatral - palavra

\begin{abstract}
This article recuperates the importance of the semiotic aspect of the theatre character's speech, which, together with its phenomenological aspect, should compose an unbreakable totality at the moment of the reception of the drama by the public. The word as the playwright's basic tool is rescued, followed by the analysis of five dramas initial fragments with the aim of verifying the pertinence of the thesis which defends the value of the semiotic component of the speech in a play.
\end{abstract}

keywords: semiotics - drama theatre speech - word 
Se, de acordo com inúmeros teóricos contemporâneos do teatro, uma crise de identidade do texto dramático se instaura a partir do final do século XIX ${ }^{1}$, se refletindo no abalo de concepções até então consensuais de mimesis, personagem, fábula e diálogo, um dos últimos elementos, senão talvez o derradeiro, cuja presença fundamental ainda se mantém quase intacta neste universo, é a palavra. Assim como a música não pode dispensar as notas, e a dança não se faz sem o movimento - considerando-se o silêncio e a imobilidade antípodas possíveis - o drama se agarra nas palavras para produzir sentido ou problematizar a falta dele, de acordo com a filiação estética do seu autor. Jean-Pierre Ryngaert, pensador francês dos estudos teatrais, conclui que:

\begin{abstract}
A obsessão pela linguagem permeia todo o teatro contemporâneo Ela assume formas particulares na medida em que corresponde à angústia de falar para não dizer nada ou sem estar de acordo consigo mesmo' da impossibilidade de falar' de se confrontar com a vertigem de palavras sempre interpreta das por quem está ouvindo.

(RYNGAERT, 1998, P.207)
\end{abstract}

Paralelamente a estas constatações teóricas, não são poucos os dramaturgos que se debruçam sobre este elemento que permanece, em seus escritos de cunho reflexivo acerca da escrita teatral, agredindo e afagando aquela que é a sua ferramenta de composição, a palavra. Nathalie Sarraute se refere a ela como: "esse fluxo de palavras que nos fascina." (SARRAUTE apud RYNGAERT, 1998, P.209); Eugène Ionesco diz que: "Em vez de ser ação ela (a palavra) nos consola como pode por não agirmos.” (IONESCO apud RYNGAERT, 1998, P.208). Henrik Ibsen, por sua vez, revela um extremo apuro para com ela, ao descrever a revisão na escrita de O Pato Selvagem em uma carta a Georg Brandes:

Eu terminei o rascunho do meu novo trabalho' uma peça em cinco atos' e estou envolvido na sua elaboração - moldando a linguagem de forma mais cuidadosa e dando um caráter mais individualizado às personagens e às falas de forma mais precisa ${ }^{2}$.

'IBSEN' 1964, P.231, tradução nossa'.

Para Jean-Pierre Sarrazac, existem duas concepções distintas, quando se discute a voz no teatro: "de um lado a 'voz' no sentido próprio, como dado físico ou fonético resultante de uma enunciação (...); e, de outro lado, uma voz dramatúrgica, ou poética, vigente nos textos dramáticos contemporâneos (...)” (SARRAZAC, 2012, P.186). Estas duas modalidades contemplam, uma pelo lado sonoro e outra pelo lado poético, um aspecto mais fenomenológico da palavra, abordando o 'como' mas deixando de fora o 'que' ${ }^{3}$. Bert States (1985), em sua obra Great Reckonings in Little Rooms, faz um esforço para aproximar os aspectos fenomenológicos e semiológicos do teatro, que para ele, estão dissociados no teatro contemporâneo. Usando o famoso 'deleitar e instruir' de Horácio, ele mostra que a busca de sentido e a busca por uma satisfação sensorial são indissociáveis em se tratando de um público de arte. Walker, ao contestar a posição de Kirby que defende a possibilidade da presença de elementos não-semióticos em uma obra teatral, afirma que: "A possibilidade de uma apresentação teatral ausente de elementos semiológicos é inexistente ${ }^{4}$." (WALKER, online, P.66, tradução nossa). Para tanto ele argumenta que se o sentido se dá a partir do contexto cultural do espectador, e estando este espectador sempre inserido em um dado contexto cultural, a ausência de uma análise semiológica por parte do espectador é impossível. Este caráter semiótico da palavra, portanto, está ligado ao conceito de enunciação. Para Ryngaert:

A análise dramatúrgica se interessa pela enunciação em dois níveis: o dos discursos dos personagens e o dos que implicitamente o autor diz para o leitor. Em vez de considerar que a fala no teatro é natural' trata'se de estudar as condições em que aparece' os pressupostos linguísticos e situacionais que a desvelam' as relações que ela pressupõe entre os personagens e também as marcas características do discurso do autor que garantem sua homogeneidade ou uma certa pertinência global.

(RYNGAERT, 1998, P.226)

\footnotetext{
1 Posição defendida sobretudo a partir da publicação de Teoria do Drama Moderno, de Peter Szondi, em 1956.

2 "I have finished the rough draft of my new work, a play in five acts, and am now engrossed in elaborating it - molding the language more carefully, and individualizing the characters and speeches more thoroughly"

3 Aqui não se pretende discutir a relação de forma e conteúdo, Adorno já o fez de forma satisfatória ao chamar a forma de conteúdo precipitado, mas a de equilibrar uma dualidade da palavra aparentemente fragmentada nestes tempos pós-modernos. 4 "the possibility of a theatrical performance devoid of semiotic elements is non-existent."
} 
Anne Ubersfeld, importante teórica da semiologia teatral, da mesma forma que Ryngaert, se debruça sobre esta questão, chegando a afirmar que: "o discurso teatral é a mais bela demonstração do caráter nãoindividual da enunciação.” (UBERSFELD, 2005, P.159). Ela problematiza o sujeito da enunciação, esclarecendo que ao lado do dramaturgo e da personagem, também farão parte desta criação de sentido da fala os artistas-mediadores, ou seja, aqueles que recebem o texto teatral, filtram-no de acordo com as suas concepções e interpretações, concretizam o que até então não passava de um material abstrato, e colocam esta enunciação em contato com o público. Afinal de contas, o texto dramático se difere se outras instâncias literárias por exatamente prever a sua apropriação por parte de um ator, ou de uma atriz.

Neste artigo não é nosso propósito examinar a questão da mediação da enunciação teatral, já tendo sido feita a consideração de sua imprescindibilidade para a realização efetiva do drama no parágrafo anterior, mas sim buscar os elementos semióticos contidos na palavra, exemplificando-os através das primeiras falas de personagens retiradas de diferentes dramaturgias, em variados contextos históricos e geográficos. A dependência que o autor teatral tem da palavra, quando os outros recursos estruturais do texto parecem não mais lhe servir, em se considerando boa parte da teoria teatral pós-moderna, remete ao apelo de Jacques Copeau aos próprios dramaturgos, uma fala que reivindica o aspecto coletivo do teatro, combina elementos tanto fenomenológicos (a inspiração) quanto semiológicos (o sentido) e clama no fim por liberdade:

Se os verdadeiros escritores não vierem me socorrer um pouco e não tentarem' junto comigo' não só elevar o nível' mas modificar o próprio sentido e a inspiração da produção dramática' para que servirá eu estar' há anos' me desdobrando para criar uma cena livre*."

(COPEAU, 2013, P.123)

Em seu livro Ler o Teatro Contemporâneo, Jean-Pierre Ryngaert (1998) faz algo semelhante, mas com um propósito outro: ele escolhe cinco inícios de peças teatrais de autores franceses chamados por ele curiosamente de 'não muito conhecidos pelo grande público ${ }^{5}$ ' para ilustrar um conceito possível de teatro contemporâneo. A nós não interessa estabelecer uma possível escola dramática, na esteira de Martin Esslin (1978) ou Hans-Thies Lehmann (2007), reconhecendo que o próprio Ryngaert diz não ter este propósito em seu exame das exposições escolhidas. Interessa sim verificar o aspecto semiológico de uma dada enunciação, aleatoriamente as primeiras dos textos dramáticos aqui selecionados, para de alguma forma recuperar este aspecto da fala, tão escanteado pela crítica hegemônica do fazer teatral na pós-modernidade. A seguinte passagem, que fala da repulsa ao autor dramático, fazendo eco à conclamação de Artaud, poderia também ser estendida ao enfoque semiológico da enunciação nos dias de hoje.

A partir dos anos ${ }^{50,}$ a escrita dramática conheceu sortes diversas. Os novos autores tiveram de en frentar a tormenta do fim dos anos ${ }^{60}$ e a desconfiança que pesava sobre a escrita' esse ato solitário $e$ vagamente elitista Alguns resistiram ao entusiasmo em favor da linguagem do corpo e do indizível. (RYNGAERT, ${ }^{1998,}$ P·XI-XII)

A palavra enquanto ferramenta principal do dramaturgo parece ser algo consensual entre os pensadores da arte dramática. Já que o diálogo se estabeleceu historicamente desde Platão como a forma de enunciação característica do drama ${ }^{6}$ (em contraposição ao eu lírico e à terceira pessoa da narrativa épica), as considerações acerca da importância da palavra estão subentendidas no termo diálogo, quando Egri, por exemplo, diz que: "Numa peça, o diálogo é o meio principal pelo qual a premissa é comprovada, as personagens reveladas e o conflito levado adiante. É vital que o diálogo seja bom, já que é a parte da peça que é mais aparente para o público 7." (EGRI, 2004, P.254, tradução nossa). Para Neipris: "O diálogo é a ferramenta fundamental do dramaturgo. É o jeito principal de se conectar com o público. Muitos dramaturgos me dizem que a razão principal

\footnotetext{
$5 \quad$ Como colocar nesta categoria autores do porte de E.Ionesco e B.M.Koltès?

6 E mesmo Szondi que questiona a idéia de conflito como a base do drama, face às mudanças na concepção do ser humano a partir do final do século XIX, ainda usa como exemplos de resolução da forma dramática autores que usam principalmente o diálogo nas suas peças, vide Miller, Wilder, Sartre e Brecht.

7 "In a play, dialogue is the chief means by which the premise is proved, the characters revealed, and the conflict carried. It is vital that the dialogue be good, since it is the part of the play which is most apparent to the audience."
} 
pela qual eles escolheram escrever pro teatro era a paixão e o talento deles pelo diálogo ${ }^{8}$.” (NEIPRIS, 2005 , P.43, tradução nossa).

Assim, será através da palavra do dramaturgo, enunciada pelas personagens por ele criada, que o leitor consegue adentrar no universo do texto e apreender as informações necessárias para a compreensão da situação dramática.

O diálogo inicial de Quem tem medo de Virginia Woolf já contém em potência a oposição básica desta peça teatral de Edward Albee:

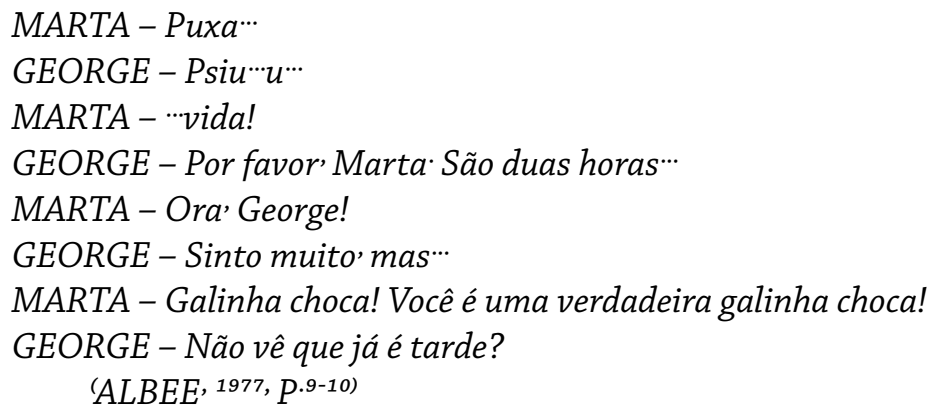

Apesar de ainda ignorantes em relação ao contexto sócio-cultural e histórico deste casal, fica claro que o homem reprime a mulher. O volume da fala dela é mais elevado, dados os pontos de exclamação, e as expressões 'por favor' e 'sinto muito' fazem do homem uma personagem mais contida, educada, mas também cautelosa e preocupada com a extroversão dela. Quem provoca o conflito é a mulher, com seu comportamento aparentemente inadequado para as normas vigentes - representadas por George - para aquele horário da manhã. A insatisfação é mútua, e o autor prefere privilegiar a relação deteriorada entre os protagonistas ao invés de localizar o leitor espaço-temporalmente. E por fim, um detalhe fundamental em qualquer texto dramático, a personagem que abre o diálogo, proferindo a primeira enunciação é Marta. Isto significa que sua figura se reveste de interesse destacado para o autor, reforçando ainda mais a função dela como instigadora do conflito principal.

Em Hamletmáquina, Heiner Müller, ao contrário de Albee, já nos dá uma referência textual de saída. Albee não reescreve Woolf. Ele dá o tom sugerindo o ambiente intelectual das personagens, usando a intertextualidade muito mais para a atmosfera da batalha conjugal entre Marta e George. Müller reescreve Shakespeare, mas a partir do título, a única informação concreta é esta. Numa escrita em que não há a indicação de personagem, tem-se apenas um subtítulo e uma enunciação que em suas primeiras linhas diz:

Eu era Hamlet Estava parado à beira-mar e falava BLA-BLA com a ressaca Atrás de mim' as ruínas da Europa Os sinos anunciavam os funerais nacionais: assassino e viúva um casal: em passo solene atrás do caixão do nobre cadáver os conselheiros' choramingando em luto mal pago. (MÜLLER, ${ }^{1987,} P^{.45)}$

Ao invés de um diálogo, aqui temos um monólogo, o que de maneira alguma impede nossa análise semiológica das enunciações iniciais de um texto dramático. Heiner Müller é tomado como um autor teatral que recusa vários princípios da dramaturgia fechada. Em Hamletmáquina temos como exemplo desta repulsa a proposital problematização da identificação do enunciador. No trecho acima, o autor além de não definir quem dá a fala, faz com que a figura cênica que enuncie este texto comece por definir não quem ele é mas quem ele era, mantendo o vácuo em relação a sua identidade. Esta lacuna, presente também quando a personagem intitulada 'Intérprete de Hamlet' afirma não ser Hamlet, ou então Ofélia no último quadro que diz ser Electra, não deixa de contribuir para a análise semiológica do texto, uma vez que as différances derridianas através da postergação de sentido auxiliam no entendimento destas personagens exatamente naquilo que elas não conseguem ser. Alguém que se apresenta dando uma informação do seu passado, mais do que impedir ao leitor saber 8 "Dialogue is the playwright's fundamental tool. It's the major way we connect with our audiences. Many playwrights tell me that the reason they chose to write for the theater was their passion and talent for the dialogue." 
quem ele é no presente, configura a sua razão de ser na própria história. O enunciador se constitui através das ausências: a de Hamlet (o texto canônico já posto em cheque) e da Europa (um continente 'em ruínas', 'de ressaca', destruído pela guerra e dependente cultural, militar e economicamente das duas grandes potências de um mundo bipolar). As palavras descrevem um funeral e sugerem metaforicamente a morte, ou melhor, as mortes: da idéia de personagem, do conceito humanista de sujeito uno, de estado-nação (os funerais nacionais). Mesmo cabendo na análise feita por Linda Hutcheon (1998) acerca do texto literário pós-moderno, que se caracteriza não pelo tema mas pela acrobacia formal que brinca com o estatuto do texto enquanto um texto, Heiner Müller não se vê tão dissociado assim da tradição, ao responder se existe alguma relação entre a sua obra e o drama aristotélico: "Vocês podem ler o texto do Hamletmáquina como uma peça de cinco atos, à maneira da dramaturgia clássica 9." (MÜLLER, 1986, P. 113, tradução nossa). Também cabe aqui ressaltar outra filiação estética do autor que aparece através dos títulos de cada uma das cinco cenas, replicando uma prática constante no teatro épico brechtiano.

Ivo Bender, autor dramático gaúcho, também inicia uma de suas peças mais conhecidas - Queridíssimo Canalha - não com um diálogo, mas com um longo aparte. Se Müller não define o destinatário da sua enunciação inicial em Hamletmáquina, Bender claramente coloca o seu protagonista Ulisses de Lamarr recitando ou cantando, conforme a rubrica, para o público. Ele diz:

ULISSES - Senhoras e senhores'
rapazes' senhoritas'
preparem'se para acompanhar
uma série de acontecimentos
nunca vistos' singulares!
O que lhes vai ser exibido
a poucos mortais é dado:
as portas desta casa
se abrem de par em par
e seus olhos engolfados em marasmo
e suas mentes só ao tédio acostumadas
poderão' enfim' testemunhar
como vive um rico homem de bem
nesta estranha capital
deste incrivel país insular!
(BENDER' 1976, P.19) $^{\text {B. }}$

Bender também faz uma crítica à situação do país em que vive, tal qual Heiner Müller. Os dois, vivendo sob períodos de ditaduras, a militar no Brasil e a comunista na Alemanha Oriental, precisam enveredar por uma linguagem fantasiosa, a fim de conseguir levar a sua obra para o público, sob risco de sofrerem a ação da censura. A Europa de Müller aqui se torna o país insular. Ulisses abre as portas de uma casa que serve de metáfora ao território nacional, praticamente xingando o estado de alienação e imobilidade em que se encontra o povo face aos mandos e desmandos dos generais. $\mathrm{O}$ apuro verbal do protagonista reflete o discurso dominante que agrada, que celebra o futebol e outros ópios do povo, enquanto que a arte de resistência é decepada. A ironia, outra característica do texto pós-moderno, aparece de forma plena na pele de um gângster que parece ter saído de uma história em quadrinhos e que até nome de estrela do cinema tem. $\mathrm{O}$ convite para conhecer a sua casa significa um convite para perceber com outros olhos - não os de 'tédio' ou 'marasmo' - o próprio contexto político do qual o público faz parte.

O diálogo apenas aparentemente sugere uma comunicação mais efetiva do que as formas solitárias, como o monólogo ou o solilóquio. Jorge Andrade, que usa basicamente o diálogo em suas peças, cria uma fricção já percebida por Peter Szondi nos autores dramáticos da virada do século XIX para o século XX, entre a possibilidade iminente de contato entre duas pessoas que de fato nunca consegue se realizar. $\mathrm{O}$ início da peça $\mathrm{O}$ Telescópio mostra isto claramente: 


\begin{abstract}
RITA - Francisco
FRANCISCO - Hummmm.

RITA - Que se passa com você?

FRANCISCO - Comigo? Nada' por quê?

RITA - Francisco! Estou falando' preste atenção!

FRANCISCO - Estou ouvindo

RITA - Por que esta atitude com a Leila e o Luís?

FRANCISCO - Que atitude?

RITA - Mal conversa com eles' Francisco.

FRANCISCO - Sobre o que posso conversar?

RITA (procura um assunto embaraçada'.

FRANCISCO - Vamos! Diga!

RITA - O que se costuma conversar com os filhos' com um genro..

FRANCISCO 'corta' - Não tenho tempo.

RITA - Não custa nada ser amável' Afinal' quiseram fazer surpresa' vindo passar uns dias na fazenda

FRANCISCO - Para mim não foi surpresa nenhuma Sabia que as coisas não andavam boas' lá pela capital
\end{abstract}

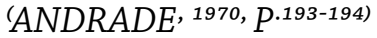

No entanto, a impossibilidade de comunicação frustrada pela sua promessa na estrutura dialógica também se revela através das enunciações do casal de velhos. Rita acha inicialmente que seu marido nem a escutando está, depois, que o fato de escutar não significa que ele presta atenção. Imediatamente, se percebe que não só os dois estabelecem uma conversação belicosa, mas que Francisco também não se interessa na comunicação com os filhos e com o genro. Este acúmulo de barreiras interpessoais se explica mediante duas oposições: a diferença de idade e o binômio fazenda x capital. O velho protagonista não sabe o que conversar com alguém tão distante de suas características identitárias.

Cabe aqui uma interessante comparação com o texto dramático de Albee analisado neste artigo, a fim de reforçar a tese de que o componente semiológico não apenas informa e situa o público permitindo que ele leia nas linhas e entrelinhas o significado das enunciações, mas também permite distinguir duas peças teatrais com um início muito semelhante. Se em Quem tem Medo de Virginia Woolf é o homem que praticamente implora que a mulher controle o comportamento, aqui, quem faz isso é a mulher. Se as semelhanças se dão pelos contextos decadentes, pela relação familiar ser a mesma, o objetivo de George e de Rita vão em direções opostas: ele quer impedir o contato de Marta com o mundo externo, ela, que Francisco passe a conviver de forma mais intensa e harmoniosa com a sua família. Em suma, podemos perceber que não é o diálogo enquanto estrutura que nos remete a uma dramaturgia fechada, mas sim o que está contido nele.

O último texto dramático que iremos analisar neste artigo, antes da conclusão final, é da autoria de uma dramaturga alemã, Theresia Walser. Se alguns autores já iniciam seus textos dando indicações claras do contexto, aqui, um pouco à la os diálogos banais de Tchekhov, conseguimos extrair apenas o elemento metafórico da enunciação, tendo que esperar um pouco mais adiante no texto para nos situarmos na trama.

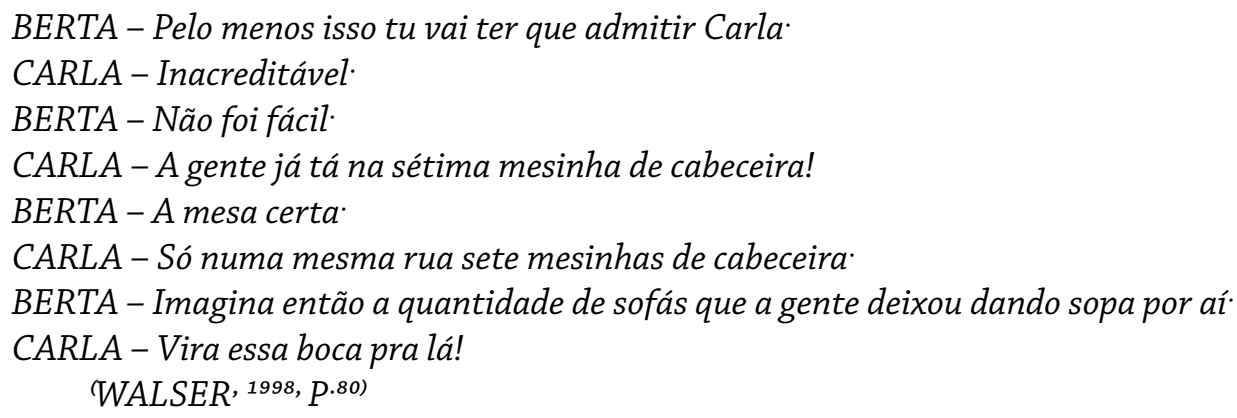

Em As Filhas de King Kong, as enunciações iniciais nos permitem depreender que, um, existe um 
grande esforço das duas no trabalho que fazem, dois, que de mesinhas de cabeceira elas já estão cheias (no duplo sentido desta palavra) e três, sofás, elas não conseguem nunca. A relação de superioridade de um sofá em relação a uma mesinha de cabeceira, até pela maior oferta deste pequeno móvel sempre escorado contra a parede, ao contrário da cor, da maciez e da posição central de um sofá, é gritante. As, informação que mais tarde no texto receberemos, enfermeiras de subúrbio parecem ter competência numa coisa, mas total fracasso em outra, que lhes daria uma satisfação maior. Elas acertam nas mesinhas (a mesa certa), mas preferem fazer de conta que não sabem que não conseguem encontrar os sofás (vira essa boca pra lá).

A discussão dos enunciados iniciais destes cinco textos dramáticos mostra que mesmo que a informação não esteja disponível de forma indireta, a possibilidade de se estabelecer uma relação com algum referencial que dote as palavras das personagens se faz sempre presente. O anseio semiológico é algo natural e privá-lo da esfera da recepção em se tratando de uma obra de arte traz o risco da frustração do público e do seu afastamento. Concordamos com a defesa de Bert States de que no teatro os aspectos fenomenológicos e semiológicos precisam andar de mãos dadas, o que remete ao clamor do filósofo Friedrich Nietzsche (1999) pela indissociação entre os princípios apolíneos e dionisíacos da arte. Nossa análise se deteve apenas em trechos curtos das peças selecionadas, o que sugere uma riqueza muito maior em termos de interpretação do sentido quando se tem o texto inteiro. De qualquer forma, o intento era o de mostrar que mesmo com pequenos fragmentos a importância da vertente semiológica na leitura de uma obra já se apresenta. O pensamento hegemônico pós-moderno, que de forma tão enfática condena os elementos racionais e lógicos presentes na criação e na recepção das obras artísticas, precisa perceber que todo sectarismo compromete a riqueza do seu objeto de estudo. O que está em jogo hoje, e principalmente quando falamos de uma manifestação artística que não faz parte das obras passíveis de reprodução de Benjamin (2000), não é o triunfo intelectual de uma das partes, mas a busca por um público que nem se afaste com aquilo que lhe pareça muito hermético, mas que também não se satisfaça com concessões simplórias de estilo e de tema, preferindo uma obra teatral que parafraseando Horácio instrua e deleite, mas que acima de tudo, estabeleça uma comunicação efetiva com ele.

\section{Referências}

ALBEE, Edward. Quem Tem Medo de Virginia Woolf? São Paulo: Abril Cultural, 1977.

ANDRADE, Jorge. “O Telescópio”. Marta, a Árvore e o Relógio. São Paulo: Perspectiva, 1970.

BENDER, Ivo, Carvalho, C. “Sexta-feira das Paixões.” Entrenós. Porto Alegre: Garatuja, 1976.

BENJAMIN, Walter. A obra de arte na época de sua reprodutibilidade técnica. In: ADORNO et al. Teoria da Cultura de massa. São Paulo: Paz e Terra, 2000.

COPEAU, Jacques. Apelos. São Paulo: Perspectiva, 2013.

EGRI, Lajos. The Art of Dramatic Writing. New York: Touchstone, 2004.

ESSLIN, Martin. O Teatro do Absurdo. Rio de Janeiro: Zahar, 1978.

HUTCHEON, Linda. A Poetics of Postmodernism: History, Theory and Fiction. New York and London: Routledge, 1998.

Ibsen: Letters and Speeches. Ed. Evert Sprinchorn. New York: Hill and Wang, 1964.

LEHMANN, Hans-Thies. Teatro Pós-dramático. São Paulo: Cosac Naify, 2007.

Léxico do Drama Moderno e Contemporâneo. Org. Jean-Pierre Sarrazac. São Paulo: Cosac Naify, 2012.

MÜLLER, Heiner. Gesammelte Irrtümer: Interviews und Gespräche. Frankfurt am Main: Verlag der Autoren, 1986.

------------. “Hamletmáquina”. Quatro Textos para Teatro. São Paulo: Hucitec, 1987.

NEIPRIS, Janet. To Be a Playwright. New York and London: Routledge, 2005.

NIETZSCHE, Friedrich. O Nascimento da Tragédia ou Helenismo e Pessimismo. São Paulo: Companhia das

Letras, 1999.

RYNGAERT, Jean-Pierre. Ler o Teatro Contemporâneo. São Paulo: Martins Fontes, 1998.

STATES, Bert. Great Reckonings in Little Rooms: on the Phenomenology of Theater. Berkeley: U of California $\mathrm{P}, 1985$. 
SZONDI, Peter. Teoria do Drama Moderno. São Paulo: Cosac Naify, 2001. UBERSFELD, Anne. Para Ler o Teatro. São Paulo: Perspectiva, 2005.

WALKER, Craig S. Reckoning with States on the Phenomenology of Theater. Journal of Dramatic Theory and Criticism. Vol XI, no. 2. Spring 97. p. 65-83. Disponível em: < https://journals.ku.edu/index.php/jdtc/article/ view/1958>. Acesso em 28 de Novembro de 2014.

WALSER, Theresia. “King Kong's Töchter”. Theater Heute. Nov. 1998: 80-89. 